to have a vena cava that had become recanalized two years later. So partial occlusion seems to be as good as ligation in stopping recurrence of emboli and to have fewer sequelae; but in some patients there will be complete occlusion of the vena cava by thrombosis.

When should an operation of this kind be used in the treatment of recurrent pulmonary emboli ? When adequate anticoagulant therapy has failed or when anticoagulants are contraindicated-for example, immediately after very extensive surgical wounds, when the patient has ulcerative disease of the gut or has had a stroke, and after some extensive urological operations because of the complications of haematuria. These operations are done much more often in North America than in Britain. In the U.S.A. prophylactic venous interruption has indeed been advocated as a routine at the time of operation for caesarean section. This is going too far in the light of the results of treatment with anticoagulants, the sequelae of ligation, and the limited information so far available on operation providing partial venous obstruction.

At what level should an operation be done? If tenderness is limited to one calf and there are no signs in the thigh, ligation of the femoral vein must still be considered, especially if the patient is very ill. When there is no indication which leg is affected, or when there is evidence of thrombi in the pelvic veins, then interruption of the vena cava is the operation of choice. When there is extensive sepsis in the pelvis, ligature is still the best procedure, but if no sepsis is present partial occlusion is probably a better type of operation. However, the indications for these measures may require revision in the light of the results obtained by venous thrombectomy, when large peripheral thrombi are located by venography and removed immediately by surgery. ${ }^{16}$ This approach has become more popular since it has been shown in recent years both experimentally ${ }^{17}$ and clinically ${ }^{18}$ that many pulmonary emboli can undergo thrombolysis. It remains to be seen whether venous thrombectomy-first tried by $R$. Leriche in 1928 - will now find a permanent place in the management of venous thrombosis and pulmonary embolism. Venous interruption should be used very sparingly until its value is clear.

\section{Audio-visual Aids to Learning}

Teaching by audio-visual methods forged ahead during the second world war, when it became imperative to train large numbers of men and women to reach prescribed standards of proficiency in the shortest possible time. In the very different conditions of peacetime the techniques of teaching have for some time been studied in the light of wartime successes. In particular audio-visual procedures have been devised to give impact to the lesson being taught.

Now the British Medical Association has joined with the Life Offices' Association and the Associated Scottish Life Offices to form the British Life Assurance Trust. The trust deed was signed on 6 October by eight trustees, four representing the two life assurance associations and four the B.M.A. The objects of the trust are to promote the education of the public generally and help the practising medical profession to keep abreast of latent developments in medical technology by encouraging the production and exhibition of audio-visual aids; to distribute such aids; to act as a co-ordinating and advisory body in this field ; and to encourage and promote research into the production and effective- ness of such aids. It is also empowered to finance and produce them. For its work the trust will have a full-time director, who has yet to be appointed. It also seeks to establish and maintain standards, by applying a seal of approval on suitable material in the field of health education regardless of its source or sponsorship. Its primary tasks are firstly to rationalize the existing B.M.A. film and tape library and " hall-mark" material of a sufficiently high standard, and secondly to produce a feature film for public showing on one of several health topics. Sir Arthur Elton, chairman of Film Centre (International) Ltd., has been retained by the trust as adviser on technical matters concerning the production, distribution, and certification of films submitted to the trust for its seal of approval.

The Brynmor Jones report on Audio-Visual Aids in Higher Scientific Education ${ }^{1}$ has sharpened interest in shortcuts to teaching. Medicine may take some pride in having already freely adopted the simpler teaching aids, to mention lantern slides and sound films as but two commonplace examples. Nowadays most lectures and conferences contain an effective element of illustration, and the quality of workmanship achieved by the teaching hospitals in particular is of a high standard. Indeed, in commenting on the current position of Great Britain the report states: "Our impression had been that as a faculty it [medicine] had led the way in the use of audio-visual aids." If further substantiation is needed it is to be found in the experience of the few photographic departments that have been established to cater for the needs of an entire university-namely, that they meet a predominantly medical requirement.

The report recommends that all teaching establishments of any size should have central service units capable of producing and storing all audio-visual materials demanded locally, while at the same time being tethered loosely to a national centre engaged in research, production, and exploitation of new aids, training of staff, and co-ordination generally. In keeping with this ambitious programme the report suggests that such units should be endowed with academic status within the universities and have full representation on the appropriate committees. It follows that sufficient academic staff must be procured or trained to fill these posts. Here again, some of the more enlightened medical schools have already raised the status of their senior medical illustration staff to that of senior lecturer, though mainly in recognition of outstanding services rather than from avowed policy. It seems probable, therefore, that if the Brynmor Jones report's suggestions are to become effective a good many recruits will come from medical departments, or at least that medicine as a whole has much experience to offer. The report acknowledges that "valuable pioneer work has been done in some medical schools through the provision of central service facilities. Their example has been followed in a number of universities and colleges, but there is a widespread need for the provision of a co-ordinated communication service in most academic institutions."

Now that closed-circuit television, programmed learning. and teaching machines offer new challenges to the teacher, a good deal of field work on the best ways of using them needs to be done. This is best co-ordinated centrally. Indeed the B.M.A. has already been responsible for a careful investigation into the use of closed-circuit television in medical schools,

\footnotetext{
1 Audio-Visual Aids in Higher Scientific Education. Report of the Committee appointed in 1963 by the University Grants Committee, Department of Education and Science, and the Scottish-Education Department, under the charmanship of Dr. Brynmor Jones, ViceChancellor of the University of Hull, 1965. H.M.S.O.

arit. med. F., 1965, 1, 313 .
} 
and the findings subsequently formed the subject of a one-day conference. $^{2}$

The latest project may be seen as an extension of the Association's many interests in this field. These include the publication among the specialist journals associated with the B.M.F. of Medical and Biological Illustration since 1951, aimed at both medical teacher and illustrator, and of the British fournal of Medical Education to be launched this year.

\section{Mopping up Strontium}

Alginates are substances derived from algae, notably seaweeds. They have many industrial applications, but recently the therapeutic use of them to prevent absorption of strontium from the alimentary tract was discussed in the Annual Report of the United Kingdom Atomic Energy Authority. ${ }^{1}$

In 1964 workers in Canada showed that alginates could lower the absorption of radioactive strontium from ligated intestinal segments of rats without inhibiting the uptake of calcium. ${ }^{2}$ Later work gave similar results from intubation experiments in rats. ${ }^{3}$ The inhibiting agent employed was sodium alginate obtained from brown seaweeds (Phaeophyceae). The work now reported from the U.K. Atomic Energy Authority is the logical development of this approach, and it includes the oral administration of sodium alginate in association with the short-lived isotope strontium-85 to human volunteers. A preliminary report by R. Hesp and B. Ramsbottom ${ }^{4}$ had suggested that a useful factor of reduction (eight to ten times) in the uptake of strontium from gut to blood and thence to bone could be obtained. Later work ${ }^{5}$ showed that the factor of reduction varied with the timing of administration, but that even 20 minutes after ingesting strontium-85 the administration of sodium alginate could reduce uptake by about three times.

The action of alginates varies with their composition, and G. E. Harrison and his co-workers at the Medical Research Council Radiobiological Unit ${ }^{6}$ have confirmed in experiments with rats that, unlike most other therapeutic agents used to reduce the uptake of radioactive strontium, alginates do not diminish absorption of calcium. Moreover, an even greater protective effect is produced if the alginate used contains a high proportion of guluronic acid.

The relevance of these studies to practical therapeutics is clear, though the practical need for such treatment is limited. In fact, accidental ingestion of radioactive strontium has not so far been a problem in the medical supervision of workers in the atomic energy industry. But, if this material were accidentally inhaled, a substantial amount of it might be cleared from the respiratory tract to the gut, and in these circumstances there might be a place for alginate therapy. Similarly, public health applications might be considered if food or water supplies were contaminated.

\footnotetext{
' Unired Kingdom Atomic Energy Authority, Twelfth Annual Report and Accounts, 1965-6. H.M.S O. 10s. 6d. net.

2 Skoryna. S. C., Paul, T. M., and Waldron, E. D., Canad. med. Ass. Y., 1964, 91, 285.

- Paul. T. M., Waloron. E. D., and Skoryna, S. C., ibid., 1964, 91, 553.

: Hesp, R., and Ramshottom, B., Nature (Lond.), 1965, 208, 1341 . Strontium Metaholism 1966 (Academic Press) (in press).

- Harrison, G. E. Humphreys, E. R., Sutton, A., and Shepherd, H., Science, 1966. 152. 655 .

' Dolphin, G. W., and Eve, I. S., Phys. in Med. Biol., 1963, 8, 193.

- Madshus, K., Strömme, A., Bohne, F., and Nigrovié, V., Int. Ұ. Radiat. Biol., 1966, 10, 519 .
}

Most of these possibilities are essentially speculative. However, G. W. Dolphin and I. S. Eve ${ }^{7}$ have shown that about half the strontium in the body has entered the bone in a little under three days; once the material is incorporated in bone its removal becomes very difficult. It is therefore worth while to define a method of prompt therapy which can act by inhibiting either primary absorption from the gut or resorption from intestinal juices during subsequent metabolism. A similar therapeutic approach applicable to intake of caesium has been described with ferri-ferrocyanide (Prussian blue) as the inhibiting agent. ${ }^{8}$ Isotope dilution techniques and chelating agents are therapeutic measures that have been used effectively against other radioactive substances, and these new studies extend the scope of treatment.

\section{Arms and the Man}

Part of the stock-in-trade of the magician-physician in folklore was the reattachment of severed portions of the human body. St. Nicholas of Bavaria, ${ }^{1}$ who joined together the separate pieces of three children who had been butchered by an innkeeper short of bacon, was an outstanding example of success in this field. In recent years, however, advances in technique have made surgical restoration of limbs a feasible proposition, and if the criterion of success is the restoration of an extremity that is aesthetically and functionally superior to an artificial limb this can nowadays certainly be achieved with an $\mathrm{arm}^{2-6}$ but only doubtfully with a leg. ${ }^{7}$ Apart from the need for technical skill on the part of the surgeon, particularly in the repair of small vessels, the outcome of the operation depends on the extent of the damage to the limbs, the level of amputation, and the period of ischaemia. As might be expected, the more proximal the amputation the more doubtful the result, mainly because the further the regenerating axons have to flow the greater is the likelihood of irrecoverable degeneration of their sheaths and the muscles they innervate. Furthermore, the more muscle there is in the severed portion the greater is the risk of metabolic acidosis when the ischaemic part is reconnected to the circulation. ${ }^{8}$ There is also a risk of ischaemic contracture. A time interval of up to six hours before restoration of the circulation is certainly consistent with success, but the period could probably be lengthened by cooling the severed part, and certainly by perfusing it. ${ }^{9}$ First-aid workers and others should be encouraged to send or take severed parts to hospital, preferably packed in ice.

When the circumstances are favourable the following steps should be taken after preparing the parts for operation. The severed part should be perfused with $10 \%$ heparin and penicillin solution. The two stumps should be trimmed, sacrificing enough bone to ensure comfortable repair of the

I Brtt. med. 7., 1962, 2, 1673

2 Kleiner, H."E., and Kasdan, M. L., Clin. Orthop., 1963, 29, 29.

s Malt, R. A., and McKhann, C. F., F.' Amer. med. Ass., 1964, 189, 716. Horn, J. S., Lancet, 1964, 1, 1152

Proc. roy. Soc. Med., 1966, 59, 587.

Herbsman, H., Lafer, D. J., and Shaftan, G. W., Ann. Surg., 1966 $163,137$.

Huang, C.-T., Li, P.-H., and Kong, G.-T., China med. 7., 1965, 84, 641.

Paul. H. A., Mehl, R. L., Schneewind, J. H., and Beattie, E. J., 7. Trauma, 1965, 5, 349.

- Snyder, C. C. Knowles, R. P., Mayer, P. W., and Hobbs, J. C., Plast. reconstr. Surg., 1960, 26, 251 .

${ }^{10}$ Kleinert. H. E., and Kasdan, M. L., F. Trauma, 1963, 3, 461.

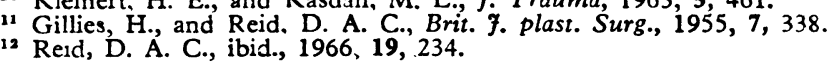

